\title{
EN TORNO A UNA IDEA METANORMATIVA DE LA JUSTICIA CONSTITUCIONAL ${ }^{1}$
}

\author{
JOSE LUIS CASCAJO CASTRO \\ Catedrático de Derecho Constitucional \\ Universidad de Salamanca
}

\author{
SUMARIO \\ I. Dificultades propias del tema \\ II. Recordatorio de algunos presupuestos \\ básicos \\ III. Partidos políticos y justicia constitucional \\ IV. Sobre el estatus del magistrado constitu- \\ cional \\ V. Conclusiones
}

\section{DIFICULTADES PROPIAS DEL TEMA}

La singular naturaleza institucional de la justicia constitucional presenta un cierto carácter enigmático que dificulta su comprensión. En este sentido se explica su consideración como cuestión recurrente de la Teoría Constitucional.

Basta echar un somero vistazo a las fuentes sobre la materia para comprobar la veracidad de la anterior afirmación. Para algunos autores su misma existencia era el signo de una situación constitucional crítica (C. Schmitt). Para otros el control jurídico de la Constitución no pertenece en modo alguno a las consecuencias necesarias del Estado de Derecho o de la Democracia (U. Scheuner). También hay quien la entiende como una casta sacerdotal, afanada únicamente en sostener la plausibilidad de sus propias convicciones morales (R. Dworkin).

Hay autores muy conscientes de que estamos en presencia de una nueva institución que modifica las relaciones de poder (D.Rousseau), y

1 Una versión de este trabajo ha sido publicado en el libro homenaje al prof. G. Peces-Barba, Madrid, 2008. 
que su tarea de interpretación de la Constitución es lo que le consienten decir sobre élla, quienes actuan constitucionalmente en los otros órganos del gobierno (J. Rawls).

Además un sector muy autorizado de la doctrina alemana insiste en que el poder del Tribunal Constitucional se basa sólo en su prestigio y en la fuerza persuasiva de sus argumentos (K. Hesse), de dónde se deduce que cuando el Tribunal decide de modo incoherente su autoridad se resiente (Ch. Starck). La crisis de la justicia existe cuando los Tribunales Constitucionales se limitan a ponderaciones tacticistas incardinadas en un pragmatismo ocasional y ecléctico (J.J. Gomes Canotilho).

En la literatura anglosajona encontramos también opiniones de distinto signo. Para unos, los tribunales constitucionales convierten a la Constitución en un documento vivo que moldea y dirige el ejercicio del poder político, en vez de ser una colección de aspiraciones y frases elegantes (D.L. Horowitz) y para otros cumplen una función especializada y redundante y son como los inspectores de control de calidad en una fábrica de automóviles(Waldron).

A la vista de estos testimonios lo cierto es que no resulta nada fácil examinar la atipicidad de una institución que es juez y órgano constitucional al mismo tiempo. Como juez se trata de una institución que opera con múltiples elementos de conocimiento sobre muy diversas cuestiones con el fin de adoptar complejas decisiones. Es este resultado final en forma de Autos, Sentencias y Decisiones, al que accedemos desde fuera, lo que justifica funcionalmente la existencia de la justicia constitucional. Pero no basta el estudio de su jurisprudencia para entender bien la posición de la misma en el sistema político del Estado constitucional democrático ${ }^{2}$. Como órgano debe defender también su propia competencia en el seno del sistema político y del ordenamiento constitucional.

Todo tribunal constitucional se ve en la difícil tesitura de tener que dar razones como órgano y argumentos como juez. No debe ser entendido como un instrumento de poder, solidario y conformista con la orientación política de la mayoría parlamentaria ${ }^{3}$, pero tampoco puede ser manipulado como me-

2 Como ha escrito P. Háberle, en este tipo de Estado la política y el derecho no se colocan en planos contrapuestos sino que más bien deben ser considerados como aspectos parciales, es decir, partes de las funciones que corresponden a la "res publica" en su totalidad, en "La Verfassungsbeschwerde nel sistema della giustizia costituzionale tedesca", traducción y presentación de A. D’Atena,ed. Giuffrè, Milán, 2000, p.15, dónde añade: Sólo en términos cuantitativos y jurídico-funcionales puede decirse que un Tribunal constitucional no haga política respecto al legislador; pero una diferenciación de naturaleza cualitativa difícilmente se logra captar. Cfr. también entre nosotros M. AHumada Ruiz, "La Jurisdicción constitucional en Europa", Ed. Thomson-Civitas, 2005.

3 En la presentación del no 4 de la Revista Fundamentos, editada por la Junta General del Principado de Asturias, p.18, J.L. REQuejo denuncia diversas técnicas de la justicia constitucional : la interpretación conforme, sentencias manipulativas, disociación de pares tan inescindibles como la inconstitucionalidad y la nulidad, administración en el tiempo de los pronunciamientos de inconstitucionalidad, como "expresivas de una filosofía que se resume muchas veces en la obsequiosidad más rendida para con el legislador del momento". 
canismo antinatural de oposición política, porque esa no es ni su naturaleza ni tampoco su función.

La situación por la que atraviesa hoy, entre nosotros, en el 2007, esta cuestión que parecía relegada ya definitivamente a los manuales didácticos, pone de relieve que no acaba de ser bien comprendida por la escasa y grosera cultura institucional de los actores políticos. Pienso que ya va siendo hora de que la entiendan. Tampoco parecen entenderla, en opinión de F. Rubio, algunos miembros muy cualificados del Poder Judicial. ${ }^{4}$

La llamada doctrina académica sobre la materia ha hecho sin embargo un esfuerzo valioso, que ha ido acompañando - a veces con un logrado intercambio de roles entre Profesor y Magistrado- el proceso de desarrollo de la justicia constitucional en todo el extenso ámbito del Derecho Comparado.

En la redacción de estas notas, desde una óptica decididamente estrábica, he intentado observar, no sin cierto asombro, recientes acontecimientos de nuestra jurisdicción constitucional con los esquemas propios de sistemas muy afines como el italiano y el alemán, preferentemente, que no en vano han tenido una innegable importancia en el origen y desarrollo del Tribunal Constitucional.

El estado de la cuestión aparece bien reflejado de forma un tanto clásica "a lo Montesquieu" en este párrafo de J.L.Requejo: "Todo apunta a una crisis estructural y de principio que, como todas las de esta especie, sólo puede resolverse con una fórmula sobradamente conocida: la división de los poderes que hoy son materialmente los de siempre, pero formalizados de manera acomodada al objetivo de superar las fórmulas que hasta ahora han podido atenazarlos. Sencillamente no están hoy dónde un día estuvieron y pudieron ser dominados. Localizarlos y definirlos es el primer paso para poder de nuevo embridarlos y asegurar aquel espacio para la libertad tras el que andamos desde hace tres siglos" ${ }^{5}$.

Hace ya tiempo que se sabe que las mayorías parlamentarias no son por sí mismas infalibles ni tampoco tienen que ser consideradas, obligatoriamente, como naturales observadoras de las normas constitucionales. Pero también es cierto que a estas alturas del desarrollo de la justicia constitucional resultaría limitador un entendimiento de la misma como jurisdicción de mera anulabilidad, simplemente de "contrarius actus", y por tanto sólo portadora de soluciones no creativas de derecho.

La legitimación de la justicia constitucional no se ajusta a la de los órganos constitucionales que ejercen parcelas notables de poder político. Hay que

4 Cfr.»El guardián de la Constitución”, en Revista Claves de razón práctica, n. 142, dónde se puede leer que: "Los jueces, que al aplicar la Contitución se convierten inevitablemente en actores de la "política constitucionalizada", entran en ella no ya sólo como defensores de las diversas posturas axiológicas existentes en la sociedad sino también como portadores de interese propios, personales o institucionales, que juegan un papel importante en la determinación de sus relaciones con los demás actores del debate político". Aunque parece obvio que esta tesis vale tanto para los magistrados del Tribunal Supremo como del Tribunal Constitucional.

5 Cfr. op. cit. p. 19. 
buscarla en la función que cumple. Y presta un estimable servicio en la medida en que posibilita una estructura dialógica y una actitud crítica frente a las confrontaciones sociales, haciendo del pluralismo una virtud ${ }^{6}$.

También se ha insistido recientemente ${ }^{7}$ en la figura del juez constitucional como institución que refleja la estructura dialógica de la representación política, como elemento democrático en cuanto que protege derechos fundamentales que son parte integrante del principio democrático y en suma como espacio de deliberación del nuevo régimen institucional y político de producción de la voluntad general en un sistema de democracia continua.

"No es un vicio democrático el que una comunidad política ofrezca a sus miembros el foro deliberativo de un tribunal constitucional" afirma Lawrence G. Sager en su conocida obra, recientemente traducida al español ${ }^{8}$.Y también la ya larga experiencia de la justicia constitucional europea permite sostener que dejó tiempo atrás su connotación de limitación antidemocrática de la soberanía parlamentaria, para entenderse como un elemento más de la misma.

Hay también quien subraya la consideración del tribunal constitucional como órgano de cierre y de garantía del sistema. Pero resulta obligado añadir que para éllo se requiere, al menos como condición necesaria, un mínimo acuerdo entre los órganos constitucionales con legitimación activa "pro bono pacis et pro amicitia conservanda". Condición que en la dinámica política no siempre se cumple.

Cabe incluso pensar, en algunos casos, que son las misma fuerzas políticas quienes no están interesadas en el fondo con potenciar un robusto órgano final de garantías constitucionales. Quitando todo relieve constitucional al mismo pretenden acentuar su componente judicialista tanto en el aspecto orgánico como en el funcional. Y en el peor de los supuestos lo convierten en campo de confrontación de la pura lucha político-partidaria, sin advertir que de este modo es el sistema en su conjunto quien resulta perjudicado. Un sistema que, a juzgar por los comportamientos de sus principales actores, no es claramente consciente de cuáles son los límites de la legalidad constitucional, acaso porque cree disponer libremente de élla.

6 Cfr. C. Pinelli, "Il dibattito sulla legittimazione della Corte Suprema", en la www.associazionedeicostituzionalisti.it/materiali/convegni/aic200610/index.html-10k—, dónde recoge la doctrina norteamericana más importante sobre la materia, para concluir que:"La pretesa di monopolio sull'interpretazione costituzionale è una manifestazione di potere solitario di cui il costituzionalismo induce a diffidare. Non meno della democracia, il principio di separazione dei poteri e il rispetto della rule of law richiedono una Corte aperta al confronto con interpretazioni rivali; e una Corte non farisaica, ma disposta a riconoscere il potere di cui dispone, perché corrispondente a un compito che è parte di un impresa comune".

7 Cfr. D. Rousseau, "La legittimità del controllo di costituzionalità delle leggi", dónde concluye que la justicia constitucional vuelve visible lo que el modelo representativo pretende olvidar, representando a la representación y reconduciendo la construcción de la norma no a un autor,- pueblo,elegidos o jueces-, sino a un espacio de deliberación que no pertenece a ninguno.

8 "Juez y Democracia", con estudio introductorio de V. Ferreres, Marcial Pons, Madrid,2007,p.223. 
Para dar más verosimilitud a este estado de cosas ayuda también una cierta visión de los medios de comunicación según la cual todo es política y el propio tribunal constitucional no pasa de ser un epígono del sistema político. De este modo, con su escasa competencia para entender las motivaciones y no digamos ya los matices de las decisiones jurisprudenciales, sientan doctrina canónica y popular, reduciendo la actividad de la justicia constitucional a un juego en blanco y negro de suma cero, es decir de ganadores y perdedores. ${ }^{9}$

\section{RECORDATORIO DE ALGUNOS PRESUPUESTOS BÁSICOS}

Con el crecimiento sin continencia de los repertorios jurisprudenciales de justicia constitucional se ha producido una especie de virtuosismo glosador de la misma, que funciona como un sistema auto-referencial sólo apto para especialistas. Pero la experiencia demuestra que no basta en este campo el manejo de los habituales métodos de la interpretación judicial, sino que requiere también de cierta competencia en el conocimiento de los postulados científicos de la Teoría Constitucional así como una buena dosis de sensibilidad política. Para J.J. Gomes Conotilho " es éste uno de los "pasos" obligatorios de la justicia constitucional comprensiva: saber si la normatividad de la interpretación/concretización judicial de la Constitución dispone de métodos para alcanzar los límites de autorreferencia del sistema constitucional». ${ }^{10}$

En general puede decirse que en el seno de la justicia constitucional toda interpretación judicial de corte estrictamente positivista-legalista infravalora el grado de ductibilidad que contiene el texto constitucional formal y puede conducir a una lectura claudicante de las funciones asignadas al máximo órgano de garantías constitucionales. En este sentido parece oportuno recordar la idea de la jurisprudencia constitucional alemana según la cual del contenido global de la Constitución se desprenden determinados principios de Derecho Constitucional y decisiones fundamentales a las que están subordinadas las singulares disposiciones constitucionales. Por tanto cada disposición constitucional debe venir interpretada de modo que resulte compatible con aquellos principios constitucionales elementales y con las decisiones fundamentales del legislador constitucional ${ }^{11}$.

Todo tribunal constitucional maneja criterios de conveniencia y, dando por supuesto su vinculación al dato positivo, dispone de amplísimos márgenes de discrecionalidad dónde con frecuencia afloran valoraciones ético-políticas.

9 Cfr. Ugo Di Siervo, "Riflessioni su un’esperienza di lavoro alla Corte Costituzionale",en Giornale di Storia Costituzionale,2006, n 11.

10 Cfr.en la rev.cit. Fundamentos 4/2006, su trabajo "Jurisdicción constitucional y nuevas inquietudes discursivas. del mejor método a la mejor teoría", p.439.

11 Cfr. BVerfGEE 1, 32 y ss., 19, 227 y 30, 19. 
La tutela de la Constitución se somete a las condiciones y exigencias propias de la forma judicial. Esto no quiere decir que esta forma judicial se despolitice sino que más bien se desplaza hacia el campo de gravitación de las cuestiones constitucionales. Y este desplazamiento suscita problemas tanto sustantivos como de legitimación sobre todo en un Estado organizado de manera democrática. ${ }^{12}$

Además resulta evidente que por su forma de composición, competencias y efectos de sus decisiones, la posición de la justicia constitucional en el sistema político y en el ordenamiento constitucional suscita siempre viejas y nuevas cuestiones ${ }^{13}$.

Tan presente está el sesgo forense del tribunal constitucional como un tribunal judicial de última instancia a disposición de cualquier interés jurídicamente protegido, carente claramente de relevancia constitucional, que se olvida con frecuencia su condición de órgano autónomo e independiente en relación con todos los demás órganos constitucionales del Estado.

Como recuerda un sector de la doctrina alemana, el juez constitucional no puede ser valorado con el mismo metro que se emplea para medir al juez ordinario civil o penal. En primer lugar porque se ocupa de un Derecho como es el Derecho Constitucional que reparte posiciones de poder y de decisión; regula y estabiliza el proceso político y por tanto el objeto sometido al examen de esta jurisdicción viene afectado, particularmente, por las tensiones propias de la dinámica del poder político. En segundo lugar porque las partes procesales suelen ser órganos constitucionales ó supremos titulares del poder político. Y por último, porque sus decisiones no están cubiertas por el techo del ordenamiento jurídico-legal existente, es decir, tiene menos apoyo en el sistema jurídico de lo que tenga la jurisdicción ordinaria, lo que termina por requerir un mayor apoyo institucional que en gran medida supone contar con un grado muy alto de aceptación. ${ }^{14}$

En mucho de los procesos constitucionales la protección de la situación de las partes no puede entenderse sino como mero efecto reflejo de la garantía objetiva del Derecho, en este caso, de la propia Constitución. ${ }^{15}$ La

12 Cfr. por todos E.-W. BÖCKENFÖRDE, «Verfassungsgerichtbarkeit. Strukturfragen,Organisation, Legitimation", en su libro "Staat Nation Europa",Ed. Suhrkamp, Frankfurt am Main, 1999,p.157 y ss.

13 "Il fatto è che i problemi connessi al rapporto tra giustizia costituzionale e sistema politico non solo sono sempre esistiti in tutti i Paesi che hanno adottato sistemi di giustizia costituzionale, ma tendono,oggi, ad assumere un rilievo crescente", en E. CHELLI, "Il giudice delle leggi", Il Mulino, Bolonia, 1996, p.45.

14 Cfr. op. cit. en nota 11. La jurisprudencia constitucional alemana ha sostenido con rotundidad que al legislador ordinario no le está permitido establecer una interpretación auténtica de la constitución. Como dice en Bverfgee 28260 y ss .el criterio para la interpretación de disposiciones de derecho constitucional no viene dado por el sistema de normas, institutos e instituciones que por rango se sitúan por debajo de la constitución, sino que más bien al contrario son estas disposiciones las que suministran las bases y el cuadro, a las que deben adecuarse las otras argumentaciones y las interpretaciones jurídicas.

15 Cfr. G. Zagrebelsky, "Giudizio <a quo> e promovimento del processo costituzionale", Giuffrè, Milán, 1990, p.110. Sobre este punto existe una doctrina y jurisprudencia muy rica y ya inabarcable en cualquiera de los países con sistemas avanzados de justicia constitucional. 
misma acción procesal del demandante en el Recurso de inconstitucionalidad debería verse como medio de garantía del ordenamiento. De aquí se deduce la posición del Tribunal Constitucional y sus facultades de impulso y dirección del propio proceso. Parece pues que prima más el interés objetivo del juicio que las situaciones jurídico-subjetivas de las partes. En cierta medida podría decirse que, como en el tipo de jurisdicción voluntaria, no hay litigio en sentido propio, no se ejercita la acción contra ninguno, las exigencias pedidas por el recurrente tienen un marcado carácter público y no es determinante la estructura bilateral del procedimiento.

Ya la Corte Constitucional italiana señaló en repetidas ocasiones que el proceso constitucional se desarrolla no en interés privado, sino para la tutela del interés público al respeto de las normas de la Constitución y no es, por tanto, susceptible de ser influido por las vicisitudes del proceso ordinario del que ha recibido el impulso. ${ }^{16}$ Aquí el interés individual se transforma en instrumento del interés público suministrando los elementos de un embrionario contradictorio.

Esta marcada tendencia objetiva de la justicia constitucional es una de sus notas más características. De este modo vigila el respeto al principio de separación de poderes y proporciona estabilidad al sistema. Es también deseable que se tenga en cuenta el valor y los efectos de sus decisiones en relación con lo que podríamos llamar el ambiente político general. Se abre así el campo de la denominada responsabilidad difusa de los tribunales constitucionales frente a la opinión pública, relación compleja y sutil al mismo tiempo que supera enseguida el escueto marco de legalidad posible para entrar de lleno en el mundo de las convenciones constitucionales.

\section{PARTIDOS POLITICOS Y JUSTICIA CONSTITUCIONAL}

Se ha dicho con razón que la relación de influencia entre los partidos políticos y la justicia constitucional es excesiva. Pero tampoco es equivocado sostener al mismo tiempo que resulta ser una relación necesaria.

En esta cuestión no hay modelos de validez general, pero puede servir la experiencia alemana al uso como referencia en este punto. Con una práctica de más de 50 años se ha normalizado una determinada forma de contribución de los partidos políticos al proceso de formación e integración del Tribunal Constitucional Federal ${ }^{17}$.

16 Cfr. Sentencia n48 de 1961 y la n 52 de 1986. De gran interés resulta la consulta del reciente libro "Corte Costituzionale e Processo Costituzionale nell`esperienza della rivista <Giurisprudenza Costituzionale> per il cinquantesimo aniversario", a cargo de A. PACE, Giuffrè, Milán, 2006.

17 Cfr. Manual de Derecho Constitucional, de Benda,Mainofer,Vogel,Hesse, Heyde, Ed. IVAP-PONS, Madrid, 1966, dónde en p. 844 puede leerse:"Dado el peso de la Jurisdicción Constitucional y en interés de su legitimación democrática nada hay que objetar respecto de la coherencia con la democracia de partidos y la división de poderes a que las fuerzas políticas más importantes influyan en la designación de magistrados, tanto menos cuando ninguno de los 
No hay régimen legal, por perfecto que sea, capaz de eliminar las preocupaciones de parcialidad que pueden surgir en este terreno, pues habrá de convenirse que a la postre "es asunto personal de los Magistrados elegidos mantenerse independientes en su fuero interno y no sentirse obligados sino por la Constitución". ${ }^{18}$

Por otra parte, todas las especulaciones relativas al eventual origen político de los Magistrados suelen quedar desmentidas por el propio modo de trabajo y funcionamiento práctico de estos tribunales.

En principio, la argumentación jurídica elaborada colegiadamente a ese nivel es un medio dialécticamente reflexivo, que impide lo que podríamos llamar un pensamiento alineado y simple. En cambio suelen ser muy simples y, en esa misma medida, propensos a error todos los juicios de intenciones que adjudican determinadas posiciones políticas a los Magistrados respecto al objeto de un litigio. Por eso algunos ordenamientos jurídicos mantienen una presunción absoluta de imparcialidad presente y subsistente del Magistrado constitucional. Presunción que se basa en el modo de la propia función que cumplen y que lleva a excluir las figuras de la abstención y la recusación en el seno del proceso constitucional.

Esta idea la ha expresado con precisión un ExPresidente de la Corte Constitucional italiana : "Il passato conta per il solo nostro foro interno, per il giudizio che ciascuno di noi ha di se stesso, non per gli altri giudici che partecipano al collegio. Conta cosí poco che non valgono gli ordinari principii sulla ricusazione o sull'astensione obbligatoria, relativamente ad atti compiuti e legami contratti prima dell'assunzione della carica. E anche quando, di fronte ad attachi esterni di questo o quel giudice, indicato come inidoneo a svolgere con imparzialità e indipendenza il suo compito in questa o quella causa, si è ipotizzata l'astensione voluntaria, alla fine la si è scartata, come un vulnus all'autonomia. La Corte è quella che è, in ogni momento della sua attività. Non siamo interessati da dove vengano i nostro colleghi. Questo riguarda chi le nomina o li elegge. Per ogni giudice conta invece, e conta molto, quel che si è e si fa in camera di consiglio, nella diuturna opera del giudicare. Se, nel lavoro quotidiano, un giudice si esponesse alla critica di essere longa manus política, la sua autorevolezza sarebbe irrimediabilmente perduta". ${ }^{19}$

Algunos autores subrayan que la colegialidad es la característica estructural más acusada de los tribunales constitucionales. Es precisamente este ras-

grandes partidos puede excederse". En este punto conviene contrastar los influjos unilaterales sobre la selección de los Magistrados, que ponen en juego la independencia del Tribunal y de modo particular es necesario tener cuidado con la politización de los nombramientos en términos partidistas tal como señala E-W. BócKENFóRDE, en op.cit.p.176 y ss. La experiencia indica que muchos Magistrados una vez elegidos han dado prueba de una gran independencia tanto externa como interna, en relación con los partidos que les habían apoyado, según P. HäBerLe en op.cit.p.7.

18 Cfr. Manual de Derecho Constitucional, cit. p. 844.

19 Vid. G. Zagrebelsky, "Principii e voti. La Corte Costituzionale e la política",Ed. Einaudi,Turín,2005, p.64. 
go el que propicia una especie de intercambio dialéctico de posiciones entre sus miembros. ${ }^{20}$

Este rasgo se traduce además en una composición natural de relaciones personales que puede alterarse y de afinidades de estilo y formas de pensar que, de modo conjunto van a verse reflejadas en el trabajo colectivo, dejando vía libre al mismo tiempo a la figura del voto particular, allí donde el ordenamiento jurídico lo permita. Esta posibilidad estuvo pensada en el pasado como premisa de un eventual "overruling" del órgano y hoy sirve también para dar cauce a matices y puntos de vista particulares de sus miembros.

En la historia de la justicia constitucional no han faltado episodios que reflejaban ataques, desde motivaciones político-partidistas, al normal funcionamiento de la institución. Algunos tuvieron éxito y se la llevaron por delante. Otros no pudieron interrumpir un proceso de desarrollo y expansión, que se considera paradigmático dentro del Derecho Comparado. En ambos casos quedó claro que un tribunal constitucional requiere de un marco jurídico que le permita blindarse frente a todo tipo de operaciones políticas por muy agresivas que sean.

De vez en cuando vuelve a sonar la vieja música del prejuicio democrático frente a la versión de una élite judicial usurpadora de la función legislativa y soberana que no le corresponde. Y de nuevo toda una literatura de choque se lanza a la defensa de uno de los bandos. El problema de las actuales formas de aristocracia del saber, del conocimiento y de la competencia profesional es que deben ser reconocidas como tales no por sus presuntos titulares sino por los destinatarios de las mismas.

El cumplimiento en forma y plazo del deber asignado a algunos órganos para la propuesta de Magistrados constituye, sin duda, un elemento que beneficia al sistema. Y hacerlo de modo que los Magistrados propuestos sean inequívocamente indiscutibles, también. Ya se que este es un terreno delicado y huidizo dónde el factor personal suele terminar siendo determinante. Pero hay que intentar objetivar todo lo que se pueda la decisión, a la búsqueda del mayor acierto posible.

A los partidos, siendo como son en la práctica señores de la constitución material, les cuesta hacerse a la idea de tener que ajustar cuentas con un árbitro de la política constitucional. En el fondo ningún partido se presta a disminuir sus propios ámbitos de influencia, y el mundo de la justicia constitucional presenta, como es sabido, un alto voltaje político que es tenido en cuenta. Pero también por esta razón el marco legal del tribunal constitucional debiera ser compartido por todos los actores del sistema.

20 Es precisamente esta dialéctica la que "a riprova definitiva della autonomia dei giudici, si manifesta in schieramenti maggioritari normalmente formati da componente di volta in volta non identicin, vid. UGO de SIERVO, op.cit.p.6. Para este autor todo esto impone la creación y el mantenimiento de una fuerte red de relaciones entre todos los jueces...la adopción de reglas de recíproco respeto y de corrección ...condividiendo un sustancial espíritu unitario. 
Los partidos políticos formalizan también pactos y acuerdos que pueden modificar los consensos básicos de un determinado ordenamiento. Además las coyunturales mayorías llevan consigo una cierta lógica transformadora que debe estar sujeta a límites. No caben operaciones de reforma que terminen por consentir una radical palingenesia de los textos jurídicos reformados. Al mismo tiempo los tribunales constitucionales en cuanto guardianes de la unidad y coherencia del ordenamiento jurídico, entendido como un bortus conclusus con su correspondiente sistema de fuentes, se abren a nuevos ordenamientos de carácter supranacional. Esta nueva perspectiva que obliga a un diálogo con instancias judiciales supraestatales supone una cierta internacionalización de los modelos de justicia constitucional existentes, que no puede dejar de ser tenida en cuenta.

También entra en juego de nuevo el papel de los tribunales constitucionales en relación con el poder de revisión constitucional, pudiendo configurarse al mismo tiempo como órganos del poder constituido y celosos custodios del poder constituyente permanente. ${ }^{21}$

Su labor en el restablecimiento del consenso y luego en su consolidación y difusión presenta un grado de máxima dificultad y resulta ser de vital importancia. Una cierta "conventio ad consociandum" debe ser entendida en este supuesto como un indispensable factor de legitimación. A su vez deberían mitigarse los aspectos más prepotentes del Estado partidocrático que alejan de la arena política a los elementos más dinámicos de la sociedad civil. No cabe olvidar que la justicia constitucional como poder político sui generis opera más allá de la clásica división entre Estado y Sociedad.

\section{SOBRE EL ESTATUS DEL MAGISTRADO CONSTITUCIONAL}

La posición de partes en el proceso constitucional se nutre de elementos del proceso civil y penal y presenta algunas analogías con el proceso contencioso-administrativo. Pero esto en modo alguno invalida la especificidad propia con la que se construyen las paredes maestras de los distintos tipos de procesos constitucionales, en todos los cuales destaca, aunque de forma diversa, un marcado carácter objetivo en defensa de la constitución.

En términos generales el marco legal de la figura de Magistrado Constitucional ha estado bien construido y ha funcionado satisfactoriamente en la práctica.

21 Cfr. L. Pegoraro, "Corti Costituzionali e Revisione della Costituzione" en los Studi in onore di U. Рототschnig, vol. secondo, Ed. Giuffrè, Milán, 2002,p.920, antes en p.913,nota n ${ }^{\circ} 28$ hace referencia al crecimiento en las motivaciones de las sentencias constitucionales, que no se limitan a "descrivere i nessi del percorso logico, magari con meri riferrimenti per relationem alle disposizioni coinvolte. Al contrario, si avvolgono di tutti gli strumenti della retorica, fanno ampi riferimenti, si richiamano al diritto comparato e alla giurisprudenza di altre Corti, operano excursus storici di istituti e discipline, esprimono valutazioni e bilanciamenti dei valori, criticano, suggeriscono, consigliano, ammoniscono i poteri dello Stato". 
Su estatuto suele estar dotado de los presupuestos necesarios y además el hecho de verse diariamente obligados a argumentar dentro de un órgano colegiado de especial cualificacción, debiera relegar a un plano marginal las posibles especulaciones sobre el origen político de sus miembros.

La forma judicial de tutela constitucional se ve también reflejada en el principio de independencia e inamovilidad del Magistrado que está además vinculado a un contexto argumentativo garantizado por un método verificable racionalmente, y sujeto a la motivación y a la rigurosa limitación de toda decisión al caso propuesto. ${ }^{22}$

Las garantías que acompañan a tan singular figura deben ser vistas no tanto como prerrogativas de las personas de los jueces, sino más bien atribuidas al órgano para el adecuado cumplimiento de sus funciones.

Los intereses que están presentes en los procesos constitucionales de carácter objetivo son intereses políticos en los que todos los magistrados deben sentirse concernidos con igual título.

Como ha ocurrido en casos semejantes, el control de constitucionalidad ha girado más hacia los supuestos concretos de las relaciones jurídicas que surgen cotidianamente en la vida social, una vez pasadas por el filtro judicial. De manera que la función del control abstracto del legislador ha resultado más comprometida políticamente y más difícil de adaptar técnicamente a los esquemas convencionales de todo proceso judicial.

La idea que debe quedar muy clara es que todo tribunal constitucional en su posición institucional de vértice tiende a desvincularse de cualquier tipo de límites ajenos. La positivización normativa de esta idea podrá cambiar de un sistema a otro, pero constituiría un error tratar de desconocerla. No se trata de proponer ningún tipo de blindaje especial, sino de reconocer el espacio natural de funcionamiento de un órgano de estas características. ${ }^{23}$

En este sentido aparece como un fenómeno incuestionable, sea cual fuere su fundamentación, la libertad demostrada por los tribunales constitucionales para desarrollar su derecho procesal con diferente alcance y extensión: desde la analogía hasta la configuración pseudolegislativa. ${ }^{24}$

22 Cfr. E.-W. BóCKENFóRDE, op. cit

23 Cfr. por todos G. Zagrebelsky, "La Giustizia costituzionale», Il Mulino, Bologna, 1988, p. 82 y ss. dónde se sostiene que en materia de normas procesales debe entenderse por lo general la prevalencia de normas propias, es decir, auto-regulación del tribunal constitucional, sobre normas ajenas o exteriores. Este punto es de especial relevancia de cara a la autonomía con que suelen regular los tribunales constitucionales , a través de su potestad reglamentaria, la posición procesal de las parte s en el proceso constitucional. "Il sistema...richiede una certa marginalizzaziones della legge ordinaria a favore della fonte di autoregolamentazione, nell'ambito della disciplina di rango costituzionale",p.85.

24 Cfr. P. Rodríguez-PATRón, "La libertad del Tribunal Constitucional alemán en la configuración de su derecho procesal", REDC, n62, 2001, p.171 y ss. Allí se insiste en el argumento de la autonomía procesal como garantía de la independencia del Tribunal Constitucional y de la propia posición que el TCF ocupa en el ordenamiento alemán. En este mismo ordenamiento la exteriorización de opiniones científicas no puede considerarse como causa de recusación de un Magistrado Constitucional desde la reforma de su Ley reguladora de 21 de diciembre de 1970 (p.174, 
A estas alturas de la experiencia habida sobre la materia, cualquier traslación mecánica procedente del derecho procesal general al campo de la jurisdicción constitucional puede ser problemática. Como ha escrito un ex Presidente del Tribunal Constitucional español "la independencia del juez constitucional puede exigir que su singular estatus jurídico afecte también a conductas personales que en sí mismas sean extrañas al ejercicio de la función jurisdiccional para proteger al magistrado constitucional frente a posibles acciones judiciales". ${ }^{25}$ Aunque por el tiempo transcurrido no hay perspectiva suficiente para enjuiciar la última reforma de la Ley Orgánica 2/1979, de 3 de octubre, del Tribunal Constitucional, efectuada por la Ley Orgánica 6/2007, de 24 de mayo, recurrida por cierto ante el propio órgano, debe repararse en el contenido de sus artículos cuarto y noventa y dos de modo particular.

No puede ser considerada como una petición de principio la afirmación de que los tribunales constitucionales ejercen sus funciones en la exclusiva defensa del interés público y de forma neutral y equidistante respecto a la pluralidad de los intereses constitucionalmente protegidos. De aquí surge su posible consideración como "juez natural" en los procesos declarativos de inconstitucionalidad de las leyes.

Como criterio general y por lo mismo más allá de los datos jurídico-positivos, no encuentro razón suficiente para no confiar a la propia sensibilidad y criterio del Magistrado constitucional la valoración de abstenerse o no en la deliberación de los asuntos concretos y también en la participación de las decisiones del tribunal constitucional. La incompatibilidad funcional que justificaría la abstención no puede apoyarse en la existencia de cualquier tipo de causa sin suficiente fundamento, como la emisión de un dictamen académico, sino en un ligamen o vínculo objetivo, absolutamente incuestionable, con una de las partes del proceso en causa. De otra manera al permitir difundirse un clima de permanente y generalizada sospecha y de suspicacia política frente a toda una legión de asesores, consultores, profesores, etc., se está impidiendo el normal funcionamiento de la institución.

Sólo una visión desconocedora ó malintencionada del modo de elaboración del trabajo jurídico puede pensar que éste es capaz de transitar con la mis-

nota p.p. $n^{\circ}$ 196). De la misma autora, vid. "La <Autonomía Procesal> del Tribunal Constitucional", Ed. Thomson-Civitas, 2003 y más recientemente "La potestad reglamentaria del Tribunal Constitucional", Ed. Iustel, Madrid, 2005, que son por lo que hace a este punto de obligada consulta.

25 Cfr. Miguel Rodríguez-Piñero y Bravo-FerRer, "La protección jurídica de la posición institucional del Tribunal Constitucional", en el vol. col. El futuro de la justicia constitucional, CEPC — TC, Madrid, 2007, p.14. Para este autor "la recusación y abstención no pueden tener el mismo alcance que en el sistema judicial, en el que la posibilidad de sustitución es mucho más abierta y dónde no existe el riesgo de manipulación política de la recusación ,puesto ya de manifiesto entre nosotros".

Sostiene, con razón a mi juicio, que los poderes públicos, incluídos los órganos judiciales, no pueden enjuiciar ni conocer de la actuación jurisdiccional del Tribunal Constitucional y de sus magistrados. Este privilegio de irresponsabilidad e inmunidad, no personal sino funcional, frente a los poderes estatales y a los jueces es un requisito necesario para mantener y asegurar la independencia del Tribunal Constitucional en el ejercicio de sus funciones.Vid.op.cit.p.18 
ma naturaleza desde un dictamen ó trabajo académico hasta el contenido de una sentencia constitucional, pasando por el trámite de elaboración parlamentaria de una norma legislativa. En estos distintos supuestos que no son fungibles entre sí difieren de forma clara tanto la finalidad como el método utilizado.

\section{CONCLUSIONES}

Como es de sobre sabido existe un efecto perverso en la relación que se produce entre los medios de comunicación y la acción de la justicia. Consiste en desatar feroces campañas sobre un órgano de justicia, unipersonal o colegiado, al que no se le ahorra un acompañamiento mediático en toda regla, y a renglón seguido exigir una exquisita libertad de criterio, base de la independencia judicial, ajena por completo a motivos que no sean los propios de la aplicación del Derecho. En el caso de la justicia constitucional, que se nutre de forma muy especial de la talla moral y el prestigio intelectual de sus miembros, resulta de vital importancia trabajar en un ambiente dónde las dudas o sospechas sobre su imparcialidad no tengan ninguna consistencia y por tanto ningún sentido.

Roza ya el sarcasmo, unido probablemente a una voluntad política torpe y maliciosa, pretender mezclar razones de índole económica que supuestamente afectarían al recto ejercicio de la justicia constitucional. Resulta chocante además que esta pretensión disfrazada en ocasiones de incidente procesal pueda hacerse valer por quienes más comprometidos están con el actual sistema de financiación de la política, uno de los aspectos más impresentables y obscuros de los sistemas políticos democráticos.

Si a lo largo de estas páginas no he hecho mención expresa de ningún tribunal constitucional en concreto, es precisamente porque creo que una cierta idea metanormativa del mismo puede servir de ayuda para el mejor entendimiento de los problemas concretos que se suscitan en el seno de las respectivas jurisdicciones constitucionales ${ }^{26}$.

Pienso también que el marco jurídico de la institución en cuestión es más débil, abierto e insuficiente de lo que pudiera dar a entender una interpretación "tout court" de las normas positivas que regulan su funcionamiento. Es cierto que un concreto orden constitucional se sostiene por sí mismo, pero no a costa de prescindir del cúmulo de variables exógenas que posibilitan su propia existencia. A estas alturas no parece que deba hacerse caso omiso del rico patrimonio jurídico que acumula la justicia constitucional comparada. Los tribunales constitucionales hoy, como describe bien L. Pegoraro, hacen amplias referencias a los precedentes, se valen del derecho comparado y de la jurisprudencia de otros tribunales constitucionales. ${ }^{27}$

26 En sentido opuesto vid. el voto particular concurrente del Magistrado Vicente CONDE Martïn De Hijas al Auto de 5 de febrero de 2007, recaido en el recurso de inconstitucionalidad n'm.8045-2006.

27 Vid. op.cit. en nota 20. 
La cultura del constitucionalismo cooperativo o, si se quiere, sostenible entre los máximos órganos del Estado permite seguir manteniendo la existencia de una tutela judicial de la constitución. Para lo cual valen aún las viejas recetas, junto a otras nuevas empíricamente contrastadas.

Se puede derogar el derecho común por razones formales y de prestigio a fin de asegurar la posición de absoluta independencia del órgano, no sólo interna sino también externamente.

La experiencia comparada pone en evidencia que las relaciones entre un tribunal constitucional y el poder judicial se han solventado con frecuencia mediante la búsqueda de un punto de equilibrio, que presupone la aceptación de un reparto de zonas de influencia (G. Zagrebelsky). De modo que el tribunal constitucional no discute al tribunal supremo su rol de órgano regulador de la interpretación judicial de las leyes y el tribunal supremo no discute las decisiones del tribunal constitucional más aparentemente creativas de derecho. También en relación con el Par-lamento se requiere un cierto sentido institucional de continencia y de prudencia por ambas partes. Tanto a la hora de regular legislativamente al órgano de garantías como también la actitud de éste a la hora de fomentar conflictos que puedan ponerle en la indeseable tesitura de considerarse a la vez juez y parte.

En el campo doctrinal español desde la temprana fijación de la cuestión, a cargo de quien fuera el primer Presidente del Tribunal Constitucional, profesor Garcia Pelayo, quedó clara la significación integradora del mismo: salvaguarda el complejo sistema de la división de poderes, custodia la línea divisoria entre el poder constituyente y el poder constituido y juzga con arreglo a criterios y razones jurídicas sobre controversias jurídicamente formuladas que versan sobre materias políticas.

Mucho más recientemente se ha insistido ${ }^{28}$ en la posición que ocupa el Tribunal Constitucional en nuestro ordenamiento. No siendo ni poder constituyente por defecto ni tampoco comisionado del poder constituyente para la defensa de la Constitución, resta su condición de intérprete supremo de la Constitución. Desde esta posición, como ya ha indicado hasta la saciedad la mejor doctrina, explicita las normas constitucionales con criterios de justicia, participando así en el establecimiento de reglas superiores de derecho, es decir, en las fuentes de creación del derecho, con la formación de normas, reglas y principios que se adhieren a las de rango constitucional.

Es probable que en el desempeño de esta función se haya excedido de su cometido. En este sentido puede afirmarse que el Tribunal Constitucional escribe demasiado, sobre todo si se piensa en los obligados lectores de su prosa cada vez más judicial. Las generosas cláusulas horizontales del título I de la Constitución interpretadas con amplitud de miras le han hecho entrar de lleno en el territorio de la legalidad ordinaria. A estas alturas de la jurispru-

28 Cfr. la Ponencia de J. GARCIA Roca "La experiencia de veinticinco años de jurisdicción constitucional en España", en el vol. col. La Reforma del Tribunal Constitucional, Ed. Tirant lo Blanch, Valencia, 2007. 
dencia, sobre todo en materias del recurso de amparo, resultaría inoperante aconsejar un cierto gusto por el sentido de la medida y de la proporción. En este sentido me parece que llega un poco tarde la última reforma de la Ley Orgánica del Tribunal Constitucional.

Es cierto que ni la Constitución ni la Ley orgánica del Tribunal Constitucional han previsto la posibilidad del control de constitucionalidad de la reforma constitucional. Pero siguiendo la idea metanormativa de la institución que me viene guiando en la redacción de estas líneas, no resulta comprensible que justamente en el momento normativo de más intensidad política, el máximo órgano de garantías del orden constitucional y centro de equilibrio del sistema de poderes quedara relegado al silencio, al menos en el examen del cumplimiento de los requisitos formales del procedimiento de reforma.

Precisamente tiene ahora la oportunidad de verificar en el actual banco de pruebas de la compleja política territorial del Estado de esta Legislatura, su condición jurídica y existencial de centro de equilibrio del sistema de poderes, con motivo de los recursos de inconstitucionalidad presentados frente al Estatuto de Autonomía de Cataluña.

Es verdad que no existe reforma legal alguna capaz de devolver el prestigio perdido a una institución del Estado. No se trata tampoco de blindar con normas el estatus del magistrado constitucional. La cuestión es de cultura institucional y pasa por un buen entendimiento previo del papel de la justicia constitucional dentro del sistema político democrático. La idea que quiero subrayar es que este tipo de justicia, sea cual fuere su configuración orgánica y funcional, presupone primero y garantiza después una determinada organización política. No se desarrolla bien en un sistema de democracia plebiscitaria ni tampoco en el seno de un sistema con poder ejecutivo prepotente. Echese un vistazo al derecho comparado y se verán fácilmente los ejemplos. No funciona adecuadamente cuando no se respeta su singular espacio institucional dentro del organigrama de un Estado democrático, e incluso dentro de espacios políticos y jurídicos supranacionales.

En suma, no es materia que pueda ser objeto de saqueo por parte de los partidos políticos. No es un tema para juristas de trinchera ni tampoco para pésimos divulgadores de trazo grueso.

Es un tipo de justicia que se legitima con la práctica por un leal y fino "idem sentire de republica" con los demás actores del sistema democrático constitucional, a los que en determinadas ocasiones tiene que controlar. Su postulada independencia debería ser además de una petición de principio, un resultado patente por su labor. Como se ha dicho con calculada ironía puede que a veces cierre un ojo y en ocasiones los dos. Pero siempre es posible volver a abrirlos, es decir, cambiar de rumbo, eso sí, con la obligación de explicarlo suficientemente.

POSTDATA: La redacción del presente trabajo se elaboró hace más de un año, al rebufo de las primeras recusaciones en relación con el Estatuto de Autonomía de Cataluña. Lo sucedido con posterioridad pone de relieve que 
siempre es posible ir a peor. De nuevo confirmo la veracidad del dicho que dice que quien lava la cabeza al asno pierde el tiempo y jabón.

ABSTRACT. - This work analyzes the singular institutional nature of the constitutional justice that is a recurrent question of the Constitutional Theory; Recent events of our constitutional jurisdiction are studied 